\title{
Cartilage-hair hypoplasia in Finland: epidemiological and genetic aspects of 107 patients
}

\author{
Outi Mäkitie
}

\begin{abstract}
Cartilage-hair hypoplasia (CHH) is an autosomal recessive form of metaphyseal chondrodysplasia characterised by short limbed short stature, hypoplastic hair growth, and impaired cell mediated immunity and erythrocyte production. The syndrome is exceptionally prevalent among the Finns and among the Old Order Amish in the United States; sporadic cases have been reported from other countries. An epidemiological and genetic study of $\mathrm{CHH}$ in Finland showed 107 patients, 46 males and 61 females, in 85 families. Eighteen of them had died, seven before the age of 1 year. The living patients ranged in age from 1 to 51 years, median 21 years. The incidence was estimated to be 1:23 000 live births. Consanguinity was found in two families and interfamilial relationships in 20 families. Geographical distribution of the birth places of the patients and their great grandparents showed accumulation in a small area in western Finland and regional clusters were seen in other parts of the country as well. The result of the segregation analysis was in accordance with recessive inheritance with reduced penetrance.

( $\mathcal{F}$ Med Genet 1992;29:652-5)
\end{abstract}

Cartilage-hair hypoplasia $(\mathrm{CHH})$ is a form of metaphyseal chondrodysplasia characterised by disproportionate short limbed short stature and fine and sparse hair. ${ }^{12}$ Skeletal growth is retarded from birth; the median adult height is $131 \mathrm{~cm}$ for males and $123 \mathrm{~cm}$ for females. ${ }^{3}$ Cellular immunity is impaired as indicated by lymphopenia and decreased in vitro lymphocyte reactivity; humoral immunity is intact. ${ }^{45}$ Deficient erythrocyte production often leads to mild transient macrocytic anaemia, and, on occasion, to congenital hypoplastic anaemia. ${ }^{6}$ The disease was first described among the Old Order Amish in the United States ${ }^{2}$ and it has also been found in the Finns in exceptionally high numbers. ${ }^{7}$ Sporadic cases have been reported in other countries. McKusick et al concluded that the mode of inheritance is autosomal recessive with reduced penetrance, since the number of patients in the families was smaller than expected.

As part of a multidimensional project on $\mathrm{CHH}$, an epidemiological and genealogical study was carried out in Finland.

\section{Patients and methods}

The material consisted of $\mathrm{CHH}$ patients diagnosed and followed at the Department of Medical Genetics or the Children's Hospital, Helsinki University Hospital, which is the major national centre for studying children with growth failure. In addition, a questionnaire study was carried out in 1988 to 1989 in each of Finland's 21 health care districts in order to attain complete ascertainment. The questionnaire was sent to the senior physicians of paediatric, medical genetic, internal medicine, and orthopaedic units of all central hospitals $(n=21)$ and district hospitals $(n=29)$ as well as to physicians in charge in health centres $(n=216)$. The questionnaire consisted of descriptions and illustrations of $\mathrm{CHH}$, diastrophic dysplasia, and achondroplasia, the three most common chondrodysplasias in Finland. Information was requested on any such patients. In case of positive answers, the patients were contacted by their own doctors, and medical records, radiographs, and detailed information on the growth failure were obtained. A clinical study was performed at the Children's Hospital if $\mathrm{CHH}$ was suspected. Furthermore, $\mathrm{CHH}$ patients were looked for and personally contacted at the meetings of the Association of Little People in Finland.

The diagnosis of $\mathrm{CHH}$ was based on short limbed short stature, generalised laxity of joint ligaments and, in childhood radiographs, metaphyseal flaring and irregularities of the growth plates. Hair hypoplasia was used only as a positive criterion; normal hair does not exclude CHH (Mäkitie and Kaitila, unpublished data). There were seven patients who had normal hair but otherwise typical features of $\mathrm{CHH}$. Two of them had a sib, and another two a relative, all with typical features of $\mathrm{CHH}$.

Since present urbanisation has mixed the possible regional clusters, differences in regional gene frequencies were assessed by the great grandparents' birth places. The patients' and their great grandparents' birth places and the great grandparents' identity were confirmed from the population register. Detailed genealogy was available for some families. For the incidence calculation the number of annual live births was obtained from the Statistical Yearbook. ${ }^{8}$ Information on abortions was obtained from parents and hospital records and was compared with the abortion frequency in the normal population. ${ }^{9}$ If the family had not been contacted recently, the number of sibs was verified from the population register. Heights of the sibs were recorded from the child health 
centres to find possible undiagnosed patients. Segregation analysis was performed with the 'singles method'10 and the 'a priori method', 1112 which both assume truncate complete ascertainment, and with the 'sib method', ${ }^{13}$ which assumes single incomplete ascertainment.

The study was approved by the ethical committee of the Children's Hospital.

\section{Results}

The epidemiological study showed a total of 107 Finnish $\mathrm{CHH}$ patients, 46 males and 61 females, in 85 families. Eighty patients had been followed at the Department of Medical Genetics or the Children's Hospital. Eighteen families with $26 \mathrm{CHH}$ patients were added through the questionnaire study and one patient through the Association of Little People. Eighteen of the 107 patients had died, seven of them under the age of 1 year. The living patients ranged in age from 1 to 51 years, median 21 years. The incidence of $\mathrm{CHH}$ calculated for the 10 year period 1977 to 1986 was 1:23000 live births, which means about three new patients yearly (fig 1 ). The frequency of spontaneous abortions was $8 \%$, which is not higher than the abortion frequency in the normal population. There was no apparent relationship between the birth order and occurrence of $\mathrm{CHH}$.

Two female patients from two Finnish families lived in Sweden. Since adequate information on their sibs or ancestors could not be obtained, they were not included in the segregation analysis. Thus, the series consisted of 105 Finnish $\mathrm{CHH}$ patients in 83 families (fig 2). Fourteen families had two affected sibs and four families had three. Altogether there were 157 unaffected sibs in the families. Using the correction for the 'singles method', the ratio of the affected sibs was 0.203 (SE 0.036). By the 'a priori method' the observed number of patients (105) was lower than expected on the basis of recessive inheritance (111, SE 5.0). The 'sib method' resulted in a ratio of 0.123 (SE 0.025 ) of the affected sibs.

The patients' and their great grandparents' birth places showed an accumulation in a small area in western Finland, Southern Ostrobothnia. Furthermore, the gene was more frequent in three other areas: the south-eastern corner of the country, Northern Savonia, and the most southern part of Lapland (fig 3). The incidence in the high frequency area of South-

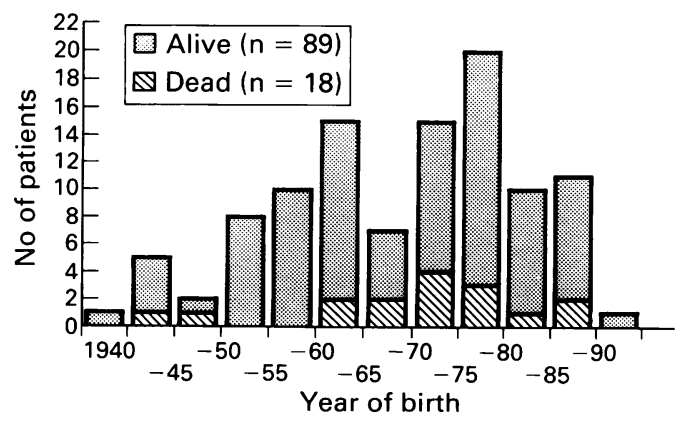

Figure 1 Cartilage-hair hypoplasia patients born in 1939 to 1991.

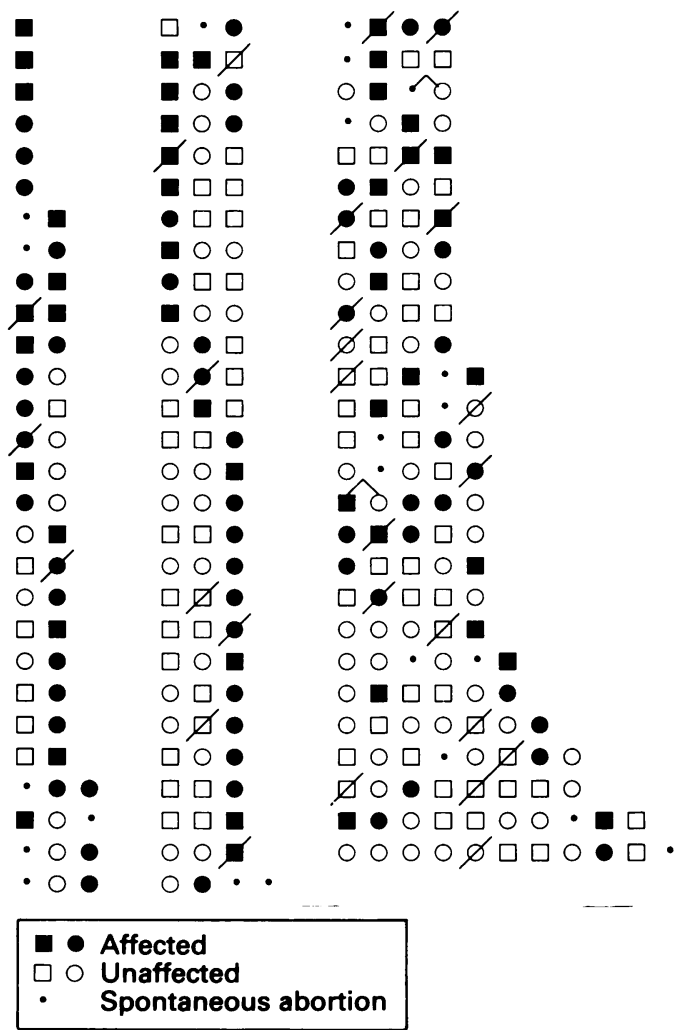

Figure 2 The 83 sibships with 105 affected, 157 unaffected, and 22 spontaneous abortions.

ern Ostrobothnia was 1:3000 live births. Consanguinity, not closer than third cousins, was found within two families, and interfamilial relationships in 20 families (fig 4). In more cases, however, possible remote relationships between the families could not be detected, since the ancestors were not traced back further than the great grandparents.

Six female patients were married to unaffected males. Two of these couples had two children and two had one child. All the children had been delivered by caesarean section and were healthy. None of the male patients was married or had children.

\section{Discussion}

Cartilage-hair hypoplasia $(\mathrm{CHH})$ is a rare inherited form of metaphyseal osteochondrodysplasia which results in severe growth failure. It is overrepresented among the religious sect of the Old Order Amish in the United States and among the Finns. At least $113 \mathrm{CHH}$ patients have been recognised among the Amish. $^{214}$ The present study showed a total of $107 \mathrm{CHH}$ patients among the Finns. The number of $\mathrm{CHH}$ patients among other nationalities is low: seven patients have been reported among the English, ${ }^{15-17}$ eight among the Dutch (van der Burgt, personal communication), and sporadic cases among the French, ${ }^{18-22}$ Germans, ${ }^{23-26}$ Danes, ${ }^{27}$ Algerians, ${ }^{20}$ Italians, ${ }^{28-30}$ Polish (van der Burgt, personal communication), Spanish, ${ }^{31}$ and Mexicans. ${ }^{32} \mathrm{~A}$ study of 403 children with bone dysplasia in Nigeria found no patients with $\mathrm{CHH}{ }^{33}$

The specific pattern of rare hereditary diseases in Finland, that is, overrepresentation of 

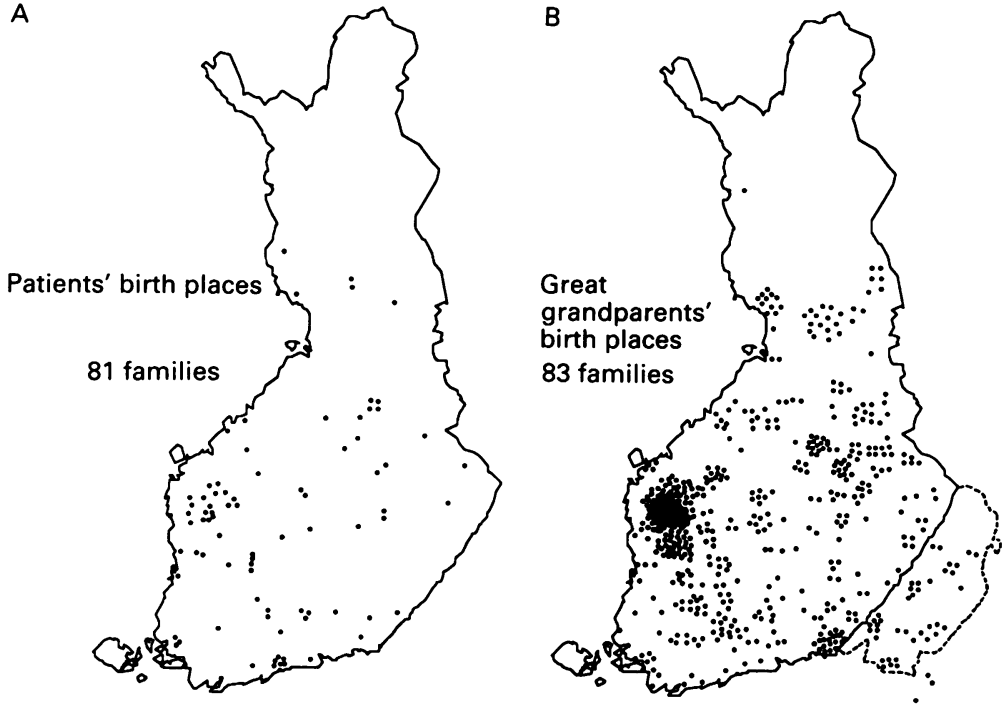

Figure 3 Geographical distribution of birth places of $(A)$ the patients and $(B)$ the great grandparents (one dot $=$ family or great grandparent). The area denoted by the broken line belonged to Finland before the second world war.

some 30 rare autosomal recessive disorders and lack of some others, is the result of national and regional isolation of the small population. . $^{345}$ Most of the ancestors of $\mathrm{CHH}$ families originated from a small area in western Finland with some regional clusters in a few eastern and south-eastern communities. These are sparsely inhabited rural areas which were permanently settled as late as the sixteenth century and are still isolated. ${ }^{35}$ Even today most native inhabitants of these communities are descendants of a few settlers from 15 to 20 generations back and are therefore remotely related to one another. ${ }^{356}$ The break up of isolates by increasing migration to towns will in the future slowly even out the clustering of recessive genes and thereby result in a decrease in the incidence of $\mathrm{CHH}$. The patients' birth places, however, still gave evidence of accumulations similar to their great grandparents' birth places. Calculated using the Hardy-Weinberg coefficient, the gene frequency for the whole country was 0.0066 and for the high frequency area of Southern Ostrobothnia 0.018 , and the carrier frequencies were $1: 76$ and $1: 29$, respectively. However, this method is partly invalidated by uneven distribution of the gene in the Finnish population. The present study showed consanguinity in two families and interfamilial relationships in 20 families. However, by tracing the ancestors back further than the great grandparents, several other remote relationships within and between $\mathrm{CHH}$ families would certainly have emerged.

In the study of $\mathrm{CHH}$ among the Amish, the number of affected was higher for females than for males (46v 31). ${ }^{2}$ Similarly, females were overrepresented among the Finnish patients $(61 v 46)$. When the two groups are combined, the sex ratio is $1: 1 \cdot 4\left(\chi^{2}=2 \cdot 14, N S\right)$.

Autosomal recessive inheritance was established in a study of $\mathrm{CHH}$ in 53 Amish sibships. However, as the number of affected patients was significantly lower than expected on the basis of the recessive hypothesis (72 $v 98.5, \mathrm{SE}$ 6.8 ), reduced penetrance of about $70 \%$ was suggested. ${ }^{2}$ The other possible explanations discussed were contamination of the series by numerous sporadic, mimicking dominant conditions, non-random chromosome segregation, gametic selection, and increased mortality in utero. ${ }^{2}$ The segregation analysis of 83 Finnish $\mathrm{CHH}$ families was performed by methods of complete and incomplete ascertainment. The ascertainment was probably close to complete among young patients, but incomplete in the older age groups, since no patients over 51 years of age were ascertained. As the ascertainment was somewhere between complete and incomplete, the corrected ratio of affected patients lies between those derived by the two extreme methods, that is, between 0.203 (SE 0.036) and 0.123 (SE 0.025). The result is in accordance with reduced penetrance. Five more patients in these families would have resulted in a ratio of 0.25 ('singles method'). The abortion frequency among the Finnish $\mathrm{CHH}$ families does not support increased mortality in utero. The lack of affected patients is too great to be explained
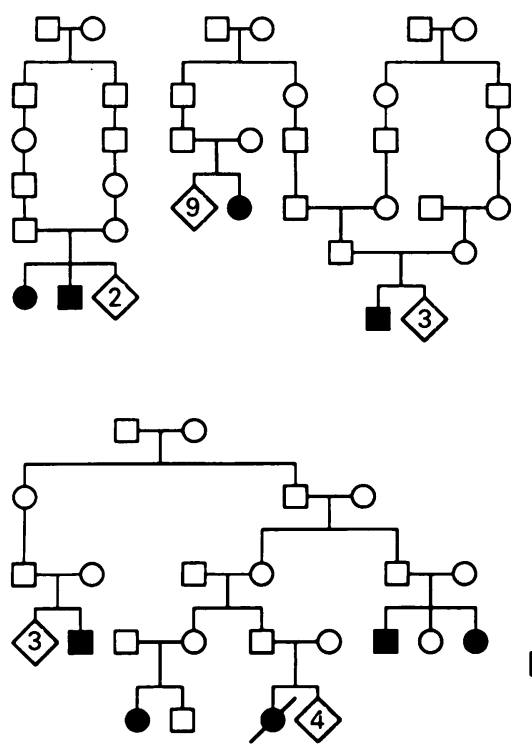
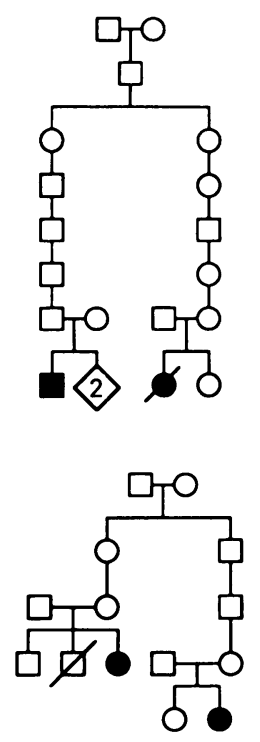
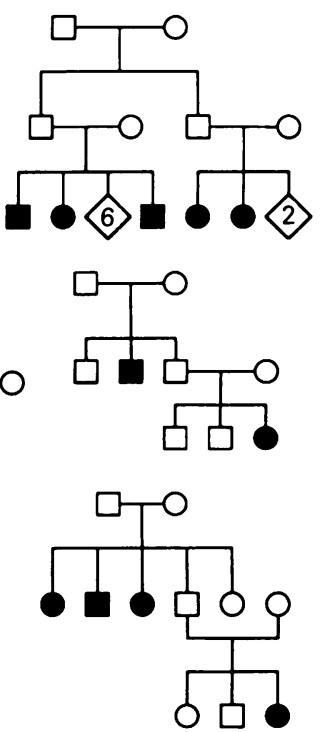

Figure 4 Pedigrees of CHH families with consanguinity (two families) or interfamilial relationships (20 families). 
by contamination by new dominant mutations and contamination by another recessive disorder should not lead to lack of affected. The other explanations, non-random chromosome segregation and gametic selection, are hypothetical and highly improbable, but difficult to prove or disapprove.

The reduced penetrance in $\mathrm{CHH}$ may be explained by some homozygotes being so mildly affected that they are presumed to be healthy. ${ }^{37}$ Among the Amish this was found in two cases: very mild $\mathrm{CHH}$, only found radiologically, in three children of affected parents, and thin hair, short and pudgy hands, and contracted pelvis in a female who was $157 \mathrm{~cm}$ tall. ${ }^{2}$ Furthermore the hair diameter in some healthy sibs overlapped that of the patients. ${ }^{2}$ In another study, lymphopenia and low response to lymphocyte stimulation were observed in a healthy sib who had no other clinical features of $\mathrm{CHH} .{ }^{38}$ In order to find mildly affected, undiagnosed persons among the Finnish $\mathrm{CHH}$ families, the relative height (deviation of height, in SD units, from mean height for age and sex) of 84 healthy sibs was compared with the midparent relative height: no difference of more than $2.0 \mathrm{SD}$ was observed. Also, the midparent relative height was always within the mean $(2.0$ SD) of the normal population. The relative heights of the patients, in contrast, were always more than 3.0 SD below the midparent relative height, and the adult relative heights ranged from $-11.4 \mathrm{SD}$ to $-4.9 \mathrm{SD}$. Childhood radiographs of the left knee were obtained from 13 healthy sibs; none of them showed metaphyseal changes. One healthy sister had poor hair growth and wore a wig; her adult height was $169 \mathrm{~cm}$ and her sitting height normal. No childhood radiographs were available for her. More thorough clinical and biochemical studies of healthy sibs are needed to settle the question of reduced penetrance.

The results of this study were consistent with those of studies of the Amish $\mathrm{CHH}$ patients. ${ }^{2}$ The number of affected persons in the families was lower than expected on the basis of a recessive hypothesis, and the affected females slightly outnumbered the affected males. No definite explanation was found and these features of the recessive $\mathrm{CHH}$ syndrome remain to be elucidated further.

I am grateful to Professor Reijo Norio, Dr Ilkka Kaitila, and Professor Jaakko Perheentupa for their comments on the manuscript. This study was supported by grants from the University of Helsinki, the Finnish Medical Foundation, the Paulo Foundation, and the Päivikki and Sakari Sohlberg Foundation, Helsinki, Finland.

1 McKusick VA. Metaphyseal dysostosis and thin hair: a "new" recessively inherited syndrome? Lancet 1964;i:832. 2 McKusick VA, Eldridge R, Hostetler JA, Ruangwit U, Egeland JA, Dwarfism in the Amish II. Cartilage-hai hypoplasia. Bull fohns Hopkins Hosp 1965;116:285-326. 3 Mäkitie O, Perheentupa J, Kaitila I. Growth in cartilagehair hypoplasia. Pediatr Res 1992;31:176-80.

4 Virolainen M, Savilahti E, Kaitila I, Perheentupa J. Cellular and humoral immunity in cartilage-hair hypoplasia. Pediatr Res 1978;12:961-6.
5 Polmar SH, Pierce GF. Cartilage hair hypoplasia: immunological aspects and their clinical implications. Clin Immunol Immunopathol 1986;40:87-93.

6 Mäkitie O, Rajantie J, Kaitila I. Anemia and macrocytosis, unrecognized features of cartilage-hair hypoplasia. Acta Paediatr Scand (in press).

7 Kaitila I, Perheentupa J. Cartilage-hair hypoplasia. In: Eriksson AW, Forsius H, Nevanlinna HR, Workman PL, Norio RK, eds. Population structure and genetic disorders. London: Academic Press, 1980:588-91.

8 Central Statistical Office of Finland. Statistical yearbook of

Finland 1990. Helsinki: Valtion Painatuskeskus, 1990:88.
9 Hemminki K, Mutanen P, Saloniemi I, Niemi N-L, Vainio $\mathrm{H}$. Spontaneous abortions in hospital staff engaged in sterilising instruments with chemical agents. $B M \mathcal{F}$ 1982;285:1461-3.

$10 \mathrm{Li} \mathrm{CC,} \mathrm{Mantel} \mathrm{N}$. A simple method of estimating the segregation ratio under complete ascertainment. $A m \mathcal{F}$ Hum Genet 1968;20:61-81.

11 Hogben $L$. The genetic analysis of familial traits. I. Single gene substitutions. F Genet 1931;25:97-112.

12 Hogben L. An introduction to mathematical genetics. New York: Norton, 1946.

13 Fisher RA. The effect of methods of ascertainment upon the estimation of frequencies. Ann Eugen 1934;6:13-25.

14 Francomano CA, Trojak JE, McKusick VA. Cartilage hair hypoplasia in the Amish: increased susceptibility to malignancy. Am f Hum Genet 1983;35:89A.

15 Savage MO. Metaphyseal dysplasia in siblings: a variant of cartilage-hair hypoplasia (case report). Proc $R$ Soc Med 1972;65:727

16 Boothby CB, Bower BD. Cartilage hair hypoplasia. Arch Dis Child 1973;48:919-21.

17 Siggers DC, Burke JB, Morris B, Normand ICS, Tanner JM, Williamson DAJ. Cartilage-hair hypoplasia. Postgrad Med $\mathcal{f}$ 1977;53:473-8.

18 Maroteaux P, Savart P, Lefebvre J, Royer R. Les formes partielles de la dysostose metaphysaire. Presse Med 1963;71:1523-6.

19 Sacrez R, Levy JM, Godar G, Castanier J. Anémie de Blackfan-Diamond associé à des malformations multiples. Med Infantile 1965;72:493-9.

20 L'Hirondel J, Caen, Daridon, Tillet. Anémie de BlackfanDiamond et dysostose métaphysaire récessive autosomique. Ouest Med 1967;20:1152-7.

21 Rubie H, Graber D, Fischer A, et al. Hypoplasie du cartilage et des cheveux avec deficit immunitaire combine. Ann Pediatr (Paris) 1989;36:390-2.

22 Le Merrer M, Briard ML, Chauvet ML, Maroteaux P. Chondrodysplasie métaphysaire récessive autosomique et maladie de Hirschspring. Ann Pediatr (Paris) 1991;38:27-30.

23 Wiedemann HR, Spranger J, Kosenow W. Knorpel-HaarHypoplasie. Arch Kinderheilkd 1968;176:74-85.

24 Beals RK. Cartilage-hair hypoplasia. A case report. $\mathcal{f}$ Bone foint Surg (Am) 1968;50:1245-9.

25 Lowry RB, Wood BJ, Birkbeck JA, Padwick PH. Cartilagehair hypoplasia. A rare and recessive cause of dwarfism. Clin Pediatr 1970;9:44-6.

26 Seige M. Metaphysäre Chondrodysplasie vom Typ McKusick (Knorpel-Haar-Hypoplasie). Monatsschr Kinderheilkd 1980;128:157-9.

27 Steffensen O, Østergaard PA. An inverted ratio for $T$ helper/suppressor cells, and selective deficiency of cellmediated immunity, in a girl with cartilage-hair hypoplasia. Eur f Pediatr 1980;135:55-8.

28 D'Apuzzo V, Joss E. Metaphysäre Dysostose und Hypoplasie der Haare: Knorpel-Haar-Hypoplasie. Beitrag zur statistischen Erfassung der Morphologie der Haare. Helv Paediatr Acta 1972;27:241-51.

29 Ventruto V, Pisciotta R, Lambertini P, et al. Su una rara forma ereditaria di condrodisplasia metafisaria: la ipoplasia cartilagine-capelli. Progr Med 1980;36:547.

30 Pinto L, Nobili B, Scarano G, Iolascon A. Cartilage-hair hypoplasia: studio clinico et immunologico. Pediat Napoli 1981;89:41-51.

31 Ray HC, Dorst JP. Cartilage-hair hypoplasia. Progr Pediatr Radiol 1973;4:270-98.

32 Sánchez-Corona J, Garcia-Cruz D, Medina C, Cantú JM, Ramos-Zepeda R, Rivas F. Increased adenosine deaminase activity in a patient with cartilage-hair hypoplasia. Ann Genet (Paris) 1990;33:99-102.

33 Adeyokunnu AA. Spectrum of bone dysplasias in African children: Ibadan Nigerian experience. In: Papadatos CJ Bartsocas CS, eds. Skeletal dysplasias. New York: Alan R iss, 1982:427-39.

34 Norio R, Nevanlinna HR, Perheentupa J. Hereditary diseases in Finland; rare flora in rare soil. Ann Clin Res 1973;5:109-41.

35 Norio R. Diseases of Finland and Scandinavia. In: Rothschild $\mathrm{H}$, ed. Biocultural aspects of disease. New York: Academic Press, 1981:359-415.

36 Norio R. Heredity in the congenital nephrotic syndrome; genetic study of 57 Finnish families with a review of reported cases. Ann Paediatr Fenn 1966;12(suppl 27).

37 McKusick VA, Eldridge R, Hostetler JA, Egeland JA Dwarfism in the Amish. Trans Assoc Am Physicians 1964;77:151-68.

38 Trojak JE, Polmar SH, Winkelstein JA, et al. Immunologic studies of cartilage-hair hypoplasia in the Amish. fohns Hopkins Med $\mathcal{f}$ 1981;148:157-64. 